\title{
Evaluation of subjective vertical perception among stroke patients: a systematic review
}

\author{
Avaliação da percepção vertical subjetiva em pacientes com acidente vascular cerebral: \\ uma revisão sistemática
}

\author{
Luana Ribeiro FERREIRA', Flávio José Pereira de Almeida FERREIRA', Fernanda Aparecida CAMPOS', \\ Gustavo José LUVIZUTTO², Luciane Aparecida Pascucci Sande de SOUZA²
}

\begin{abstract}
Background: Verticality misperception is relatively common among patients after stroke, and it may be evaluated in terms of (a) subjective visual vertical (SVV), (b) subjective haptic vertical (SHV) and (c) subjective postural vertical (SPV). To better understand these assessment methods, we conducted a systematic review of the methodological characteristics of different protocols for evaluating SVV, SHV and SPV among individuals after stroke. Objective: To standardize the methodological characteristics of protocols for evaluating verticality perception after stroke. Methods: We searched the following databases: PUBMED, regional BVS portal (MEDLINE, LILACS, IBECS, CUBMED, Psychology Index and LIS), CINAHL, SCOPUS, Web of Science, Science Direct, Cochrane Library and PEDro. Two review authors independently used the QUADAS method (Quality Assessment of Diagnostic Accuracy Studies) and extracted data. Results: We included 21 studies in the review: most (80.9\%) used SVV, eight (38.1\%) used SPV and four (19.0\%) used SHV. We observed high variability in assessments of verticality perception, due to patient positions, devices used, numbers of repetitions and angle of inclination for starting the tests. Conclusion: This systematic review was one of the first to explore all the methods of assessing verticality perception after stroke, and it provides crucial information on how to perform the tests, in order to guide future researchers/clinicians.
\end{abstract}

Keywords: Stroke; Health Research Evaluation; Verticality; Subjective Visual Vertical; Subjective Haptic Vertical; Subjective Postural Vertical.

RESUMO

Antecedentes: A percepção errônea da verticalidade é relativamente comum em pacientes após Acidente Vascular Cerebral (AVC) e pode ser avaliada pelas: (a) vertical visual subjetiva (SVV), (b) vertical háptica subjetiva (SVH) e (c) vertical postural subjetiva (SPV). Para melhor compreender esses métodos de avaliação, realizamos uma revisão sistemática das características metodológicas de diferentes protocolos para avaliações de SVV, SHV e SVP em indivíduos após AVC. Objetivo: Padronizar as características metodológicas de protocolos de avaliação da verticalidade após AVC. Métodos: Foi realizada busca nas bases de dados PUBMED, Portal Regional da BVS (MEDLINE, LILACS, IBECS, CUBMED, Psychology Index, LIS), CINAHL, SCOPUS, Web of Science, Science Direct, Biblioteca Cochrane e PEDro. Dois revisores avaliaram independentemente o QUADAS (Avaliação da Qualidade dos Estudos de Precisão de Diagnóstico) e extraíram os resultados. Resultados: Foram incluídos 21 estudos: a maioria (80,9\%) utilizando a SVV, oito (38,1\%) a SPV e quatro (19,0\%) a SHV. Observou-se grande variabilidade na avaliação da verticalidade, devido às posições dos pacientes, dispositivos utilizados, número de repetições e ângulo de inclinação para iniciar os testes. Conclusão: Esta revisão sistemática é uma das primeiras a explorar todos os métodos de avaliação da verticalidade após o AVC e fornece informações cruciais sobre como realizar os testes para orientar os futuros pesquisadores e clínicos.

Palavras-chave: Acidente Vascular Cerebral; Avaliação da Pesquisa em Saúde; Verticalidade; Subjetiva Vertical Visual; Subjetiva Vertical Háptica; Subjetiva Vertical Postural.

\section{INTRODUCTION}

Stroke can lead to multiple systemic impairments, including sensory, perceptual and cognitive disabilities. All of these can affect balance and interfere with perceptions of verticality ${ }^{1}$.
Verticality can be perceived in different manners: 1) visual perception of the vertical, evaluated by means of a subjective visual vertical (SVV) test that relies on visuo-vestibular information; 2) postural perception of the vertical, measured through a subjective postural vertical (SPV) test derived from

\footnotetext{
'Universidade Federal do Triângulo Mineiro, Uberaba MG, Brazil.

Universidade Federal do Triângulo Mineiro, Departamento de Fisioterapia Aplicada, Uberaba MG, Brazil.

LRF (iD) https://orcid.org/0000-0001-5445-5412; FJPAFE (D) https://orcid.org/0000-0001-6523-0569; FAC (DD https://orcid.org/0000-0003-4637-6954; GJL (ID) https://orcid.org/0000-0002-6914-7225; LAPSS (D) https://orcid.org/0000-0002-7160-9556

Correspondence: Gustavo José Luvizutto; Email: gluvizutto@gmail.com.

Conflicts of interest: There is no conflict of interest to declare.

Authors' contributions: GJL, LAPSS: conceptualization, data curation, formal analysis, writing - original draft preparation, project administration, supervision, writing - review \& editing; LRF, FJPAF, FAC: investigation, methodology, writing - original draft.
}

Received on December 18, 2020; Received in its final form on March 05, 2021; Accepted on March $25,2021$.

(cc) BY 
graviceptive-somesthetic information; 3) tactile or haptic vertical sense, assessed through a subjective haptic vertical (SHV) test ${ }^{2}$.

The SVV is responsible for an individual's ability to determine whether objects are aligned vertically without a visual reference point for verticality. It depends on the interaction of sensory information in the visual and vestibular systems. This type of perception is associated with peripheral vestibular information and with integration in the parietoinsular vestibular cortex and the superior temporal gyrus ${ }^{3,4}$. The SHV results from somatosensory stimulation during manual exploration of an object in space ${ }^{5}$. The SPV reflects the capacity of the body to adjust to the gravitational vertical ${ }^{6}$. In the last two types of perception, the temporo-parietal junction (TPJ) is a target region for multisensory integration and processing ${ }^{7}$. However, it needs to be emphasized that impairment of one type of perception of verticality does not necessarily imply that the other types have been compromised.

Regarding the ontogenetic process, verticality is a significant acquisition during motor development, and it is pivotal to learning to maintain an upright standing posture, in association with standard trunk control, which is the basis for motor abilities such as reaching and gait ${ }^{8}$. Stroke is the main cause of impaired verticality in adults, and this impairment impacts on balance recovery, postural deficits, functionality and limitations to activities of daily living ${ }^{9,10}$. Studying human verticality after stroke with the aim of establishing the main assessment methods can provide the best strategy for future treatment in this population.

With this assumption, some questions still need to be clarified: 1) Are there any validated methods for evaluating verticality perception after stroke? 2) How are these tests performed? To better understand these assessment methods, we conducted a systematic review of the methodological characteristics of different protocols for evaluating SVV, SHV, and SPV among individuals who had suffered stroke.

\section{METHODS}

\section{Search process and articles selected}

This systematic review followed the recommendations of the Preferred Reporting Items for Systematic Reviews and MetaAnalyses (PRISMA) ${ }^{11}$. However it was not possible to perform a systematic review of diagnostic test accuracy (DTA) because there is no gold-standard verticality test. Two investigators independently searched for all articles written up to November 2020, without restriction of dates or languages, using the following databases: PUBMED, regional BVS portal (MEDLINE, LILACS, IBECS, CUBMED, Psychology Index and LIS), CINAHL, SCOPUS, Web of Science, Science Direct, Cochrane Library and PEDro. Both researchers also searched through the reference lists of all studies selected.

We included original studies reporting empirical data from evaluations on perceptions of verticality among post-stroke patients. We included studies that assessed verticality perceptions among patients diagnosed with any type of stroke (ischemic or hemorrhagic), from the acute phase (in the first 24 to 72 hours) to its chronic phase. We excluded studies involving animal models, duplicate studies, systematic reviews, off-topic studies, editorials and commentaries not reporting empirical results.

The search strategy was as follows:

Search strategy 1: “Stroke OR [Mesh Terms]” AND “Vestibular Function Tests OR [Mesh Terms]” AND "Subjective Visual Vertical”, "Subjective Postural Vertical” and "Subjective Haptics Vertical”

Search strategy 2: "Rehabilitation OR [Mesh Terms]" AND "Vestibular Function Tests OR [Mesh Terms]" AND “Subjective visual vertical”, "Subjective Postural Vertical” and "Subjective Vertical Haptics"

Search strategy 3: "Rehabilitation [Mesh Terms]" AND "Stroke [Mesh Terms]" AND "Vestibular Function Tests OR [Mesh Terms]" AND "Subjective Visual Vertical”, "Subjective Postural Vertical" and "Subjective Vertical Haptics".

From each study, we collected data on the participants (sample size, age and gender), type and time of stroke and methodological evaluation. We assessed the methodological quality of the studies using QUADAS (Quality Assessment of Diagnostic Accuracy Studies) ${ }^{12}$. This is a validated evidence-based tool for quality assessment that is used in systematic reviews to decrease the risk of study selection bias and increase the accuracy of the conclusions drawn from the review. It contains 14 questions, and we used the adapted protocol described by Conceição et al. $(2018)^{13}$, which contains six of these questions: \#1- Was the spectrum of participants representative of participants who will receive the test in practice?; \#2- Were participant selection criteria clearly described?; \#5- Did the whole participant sample or a random selection of the sample receive verification using a reference standard for diagnosis or, at least, was it confirmed verbally that the sample did not have any disease?; \#9- Was the execution of the reference standard described in sufficient detail to permit its replication?; \#12- Were the same clinical data available when test results were interpreted as would be available when the test is used in practice?; and (f) \#13- Were uninterpretable/intermediate test results reported? Each question was scored as $0=$ study did not present this item $(\mathrm{N})$ or the item is not clear in the study (NC), or as $1=$ the study presented this item.

Here, we report on data from these studies descriptively, regarding the methodologies used for assessing subjective perceptions of verticality and the results obtained. We did not perform any meta-analysis because of the heterogeneity of the assessment methodologies used in these studies.

\section{RESULTS}

We identified 1759 studies, and after reading their titles and abstracts, 26 studies were selected for further examination. 
Among these, we excluded seven studies because they did not meet the inclusion criteria. Thus, we included 21 studies involving 806 participants that evaluated post-stroke patients' subjective vertical perceptions (Figure 1).

Data extracted from these 21 studies are displayed in Table 1. The participant sample sizes ranged from 5 to 86 and their ages from 43 to 76.5 years. The participants included had suffered ischemic and hemorrhagic strokes. The time that had elapsed from the stroke to the evaluation on verticality perceptions ranged from 19.4 days to 4.7 years. Twelve studies included participants who were in the subacute stage of stroke; three studies included participants in the acute phase; two included participants in both the acute and the chronic phase; and one study included participants in both the subacute and the acute phases. Three studies did not report stroke phase.

Table 2 shows the QUADAS results.

Among the 21 studies included in this review, most (18; $80.9 \%$ ) using the evaluations of SVV perceptions ${ }^{1,10,14-29}$, eight (38.1\%) used SPV $9,10,19,22,27,29,30,31$ and four (19.0\%) used SHV ${ }^{9,20,22,25}$.

\section{Subjective visual vertical}

Among the 18 studies that evaluated SVV ${ }^{1,10,14-29}$, six compared strokes with and without unilateral spatial neglect (USN) $)^{17,20,24,25,28,29}$. Bonan et al. $(2007 ; 2006 ; 2006)^{1,15-16}$ compared individuals with lesions in both hemispheres and correlated the results with balance impairment post-stroke, in three different studies. Bonan et al. (2006) investigated whether SVV misperception was correlated with balance difficulties in hemiplegic patients after recent stroke ${ }^{15}$. Bonan et al. (2006) showed the evolution of SVV and the factors affecting it ${ }^{16}$, and Bonan et al. (2007) evaluated the influence of SVV perturbations on balance recovery after stroke ${ }^{1}$. Four studies evaluated patients with Pusher syndrome $e^{18,19,21,29}$.

In all of these studies, the evaluation was done in a dark room in a seated position, except for Reinhart (2016), who evaluated the subjects in an orthostatic position ${ }^{23}$. Nine studies involved head, chin and trunk stabilization ${ }^{14-17,20-24}$. Karnath et al. (2000) described a position of the lower limbs in which they

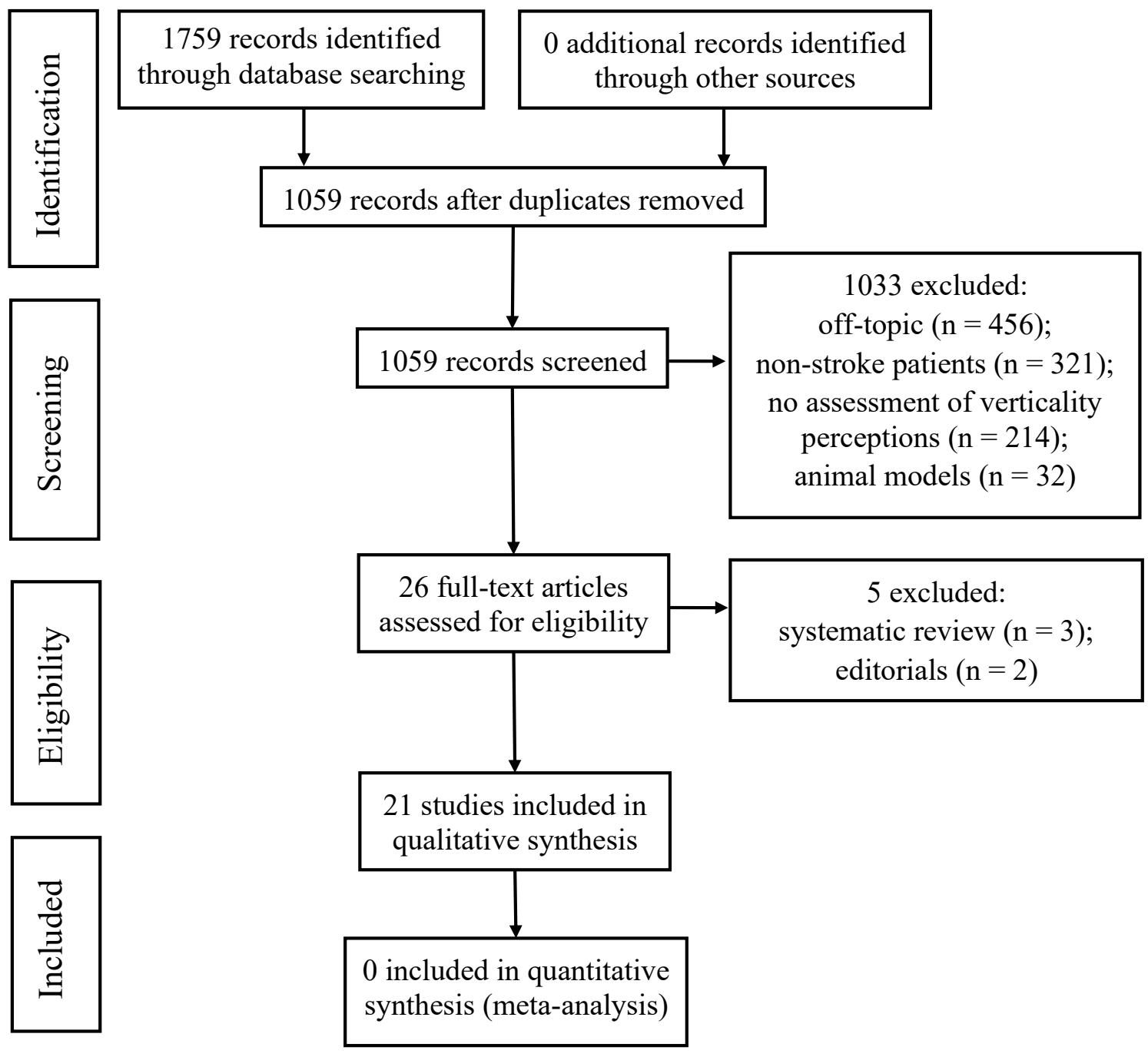

Figure 1. Flow diagram through the different phases of the systematic review. 
Table 1. Characteristics of studies included.

\begin{tabular}{|c|c|c|c|c|c|}
\hline Study & Participants & $\begin{array}{l}\text { Age (years) } \\
\text { (Mean } \pm \text { SD) }\end{array}$ & $\begin{array}{l}\text { Gender } \\
(\mathrm{M} / \mathrm{F})\end{array}$ & Aim & Verticality \\
\hline Kerkhoff (1999) ${ }^{20}$ & $\begin{array}{l}\text { Stroke with and without } \\
\text { USN* and healthy } \\
\text { individuals. }\end{array}$ & $\begin{array}{l}\text { Stroke: } 53 \pm 4.92 \\
\text { Healthy: } 51 \pm 10.06\end{array}$ & $35 / 21$ & $\begin{array}{l}\text { To test visual and haptic } \\
\text { orientation among individuals } \\
\text { with and without left USN and } \\
\text { healthy subjects. }\end{array}$ & SVV and SHV \\
\hline $\begin{array}{l}\text { Karnath et al. } \\
(2000)^{19}\end{array}$ & $\begin{array}{c}\text { Stroke with Pusher** } \\
\text { and USN }\end{array}$ & $\begin{array}{c}73.6 \pm 4.5 \\
53.4 \pm 13.57\end{array}$ & $\begin{array}{l}2 / 3 \\
3 / 2\end{array}$ & $\begin{array}{l}\text { To analyze the mechanism of } \\
\text { pushing. }\end{array}$ & SPV and SVV \\
\hline Saj et al. $(2005)^{24}$ & $\begin{array}{c}\text { Stroke with and without } \\
\text { USN }\end{array}$ & Stroke: 60 & $5 / 3$ & $\begin{array}{l}\text { To evaluate SVV among } \\
\text { individuals with and without } \\
\text { USN and to relate of the trunk } \\
\text { position }\end{array}$ & SVV \\
\hline $\begin{array}{l}\text { Bonan et al. } \\
(2006)^{1}\end{array}$ & Right and Left stroke & Stroke: 59 & $16 / 14$ & $\begin{array}{l}\text { To determine SVV } \\
\text { misperception and balance } \\
\text { after stroke }\end{array}$ & SVV \\
\hline $\begin{array}{l}\text { Bonan et al. } \\
(2006)^{16}\end{array}$ & Right and Left stroke & $\begin{array}{l}\text { RS: } 55 \pm 18 \\
\text { LS: } 52 \pm 17\end{array}$ & $\begin{array}{c}7 / 6 \\
10 / 07\end{array}$ & $\begin{array}{l}\text { To determine SVV } \\
\text { misperception after stroke }\end{array}$ & SVV \\
\hline $\begin{array}{l}\text { Johannsen et al. } \\
(2006)^{18}\end{array}$ & $\begin{array}{l}\text { Stroke and healthy } \\
\text { individuals }\end{array}$ & $\begin{array}{l}\text { Stroke: } 70 \\
\text { Healthy: } 66.5\end{array}$ & $12 / 3$ & $\begin{array}{l}\text { To investigate SVV and the } \\
\text { longitudinal axis of the body } \\
\text { after hemispheric stroke. }\end{array}$ & SVV \\
\hline $\begin{array}{l}\text { Bonan et al. } \\
(2007)^{15}\end{array}$ & Right and Left Stroke & $57.71 \pm 16.49$ & $14 / 14$ & $\begin{array}{l}\text { To assess SVV misperception } \\
\text { regarding balance recovery } \\
\text { after stroke }\end{array}$ & SVV \\
\hline $\begin{array}{l}\text { Barra et al. } \\
(2008)^{14}\end{array}$ & Right and Left Stroke & $58.88 \pm 6.3$ & $11 / 4$ & $\begin{array}{l}\text { To investigate SVV and the } \\
\text { longitudinal axis of the body } \\
\text { after hemispheric stroke. }\end{array}$ & SVV \\
\hline $\begin{array}{l}\text { Perennou et al. } \\
(2008)^{2}\end{array}$ & $\begin{array}{l}\text { Stroke and healthy } \\
\text { individuals }\end{array}$ & $\begin{array}{l}\text { Stroke: } 55.4 \pm 13.1 \\
\text { Healthy: } 48.8 \pm 10.8\end{array}$ & $\begin{array}{l}57 / 29 \\
22 / 11\end{array}$ & $\begin{array}{l}\text { To evaluate relationships } \\
\text { between verticality } \\
\text { perceptions after stroke }\end{array}$ & $\begin{array}{c}\text { SVV and SPV, } \\
\text { SHV }\end{array}$ \\
\hline Paci et al. $(2011)^{21}$ & $\begin{array}{l}\text { Stroke with Pusher** } \\
\text { and healthy individuals }\end{array}$ & $\begin{array}{l}\text { Stroke: } 76.5 \pm 10.1 \\
\text { Healthy: } 77.4 \pm 4.1\end{array}$ & $\begin{array}{l}5 / 3 \\
5 / 5\end{array}$ & $\begin{array}{l}\text { To evaluate SVV among } \\
\text { individuals with Pusher** }\end{array}$ & SVV \\
\hline Utz et al. $(2011)^{25}$ & $\begin{array}{l}\text { Stroke with and without } \\
\text { USN* and healthy } \\
\text { individuals }\end{array}$ & $\begin{array}{l}\text { Stroke: } 70.6 \pm 8.3 \\
\text { Healthy: } 69.68 \pm 9.9\end{array}$ & $\begin{array}{l}9 / 7 \\
14 / 4\end{array}$ & $\begin{array}{l}\text { To investigate both SVV and } \\
\text { SHV in the frontal and sagittal } \\
\text { plane among patients with } \\
\text { USN after stroke }\end{array}$ & SVV and SHV \\
\hline $\begin{array}{l}\text { Funk et al. } \\
(2011)^{17}\end{array}$ & $\begin{array}{l}\text { Stroke with and without } \\
\text { USN* and healthy } \\
\text { individuals }\end{array}$ & $\begin{array}{c}51.1 \pm 6.2 \\
55.6 \pm 6 \\
47.2 \pm 12.7\end{array}$ & $\begin{array}{l}6 / 6 \\
9 / 3 \\
7 / 5\end{array}$ & $\begin{array}{l}\text { To investigate SVV among } \\
\text { individuals with and without } \\
\text { USN after stroke }\end{array}$ & SVV \\
\hline $\begin{array}{l}\text { Saeys et al. } \\
(2012)^{10}\end{array}$ & Stroke & $62.77 \pm 13.56$ & $16 / 16$ & $\begin{array}{l}\text { To investigate the relationship } \\
\text { between somatosensory loss } \\
\text { and verticality perception } \\
\text { after stroke }\end{array}$ & SVV and SPV \\
\hline $\begin{array}{l}\text { Bergmann et al. } \\
(2016)^{30}\end{array}$ & Stroke with Pusher** & $71.1 \pm 8.93$ & $11 / 7$ & $\begin{array}{l}\text { To investigate SPV among } \\
\text { individuals with Pusher** }\end{array}$ & SPV \\
\hline $\begin{array}{l}\text { Baggio et al. } \\
(2016)^{9}\end{array}$ & Stroke & $64.4 \pm 12.4$ & $27 / 18$ & $\begin{array}{l}\text { To analyze the relationships } \\
\text { of SPV and SHV with postural } \\
\text { control among individuals } \\
\text { after stroke }\end{array}$ & SPV and SHV \\
\hline $\begin{array}{l}\text { Reinhart et al. } \\
(2016)^{23}\end{array}$ & $\begin{array}{l}\text { Right stroke and healthy } \\
\text { individuals }\end{array}$ & $55.5 \pm 9.3$ & $12 / 8$ & $\begin{array}{l}\text { To investigate whether } \\
\text { rotational coherent dot } \\
\text { movement (RCDM) modulates } \\
\text { spatial orientation deficits } \\
\text { of the SVV in the roll plane in } \\
\text { right hemispheric stroke }\end{array}$ & SVV \\
\hline $\begin{array}{l}\text { Jamal et al. } \\
(2018)^{26}\end{array}$ & Stroke & $60.3 \pm 10.0$ & $24 / 6$ & $\begin{array}{l}\text { To examine both egocentric } \\
\text { and allocentric space } \\
\text { representation and weight- } \\
\text { bearing asymmetry among } \\
\text { chronic stroke patients. }\end{array}$ & SVV \\
\hline
\end{tabular}


Table 1. Cont.

\begin{tabular}{|c|c|c|c|c|c|}
\hline Study & Participants & $\begin{array}{c}\text { Age (years) } \\
\text { (Mean } \pm \text { SD) }\end{array}$ & $\begin{array}{c}\text { Gender } \\
(\mathrm{M} / \mathrm{F})\end{array}$ & Aim & Verticality \\
\hline $\begin{array}{l}\text { Saeys et al. } \\
(2018)^{27}\end{array}$ & Stroke & $62.4 \pm 13.3$ & $22 / 15$ & $\begin{array}{l}\text { To explore verticality } \\
\text { perception and sensory } \\
\text { reweighting strategies among } \\
\text { stroke subjects }\end{array}$ & SVV and SPV \\
\hline Mori et al. $(2020)^{28}$ & $\begin{array}{l}\text { Stroke with and without } \\
\text { USN* and healthy } \\
\text { individuals }\end{array}$ & $67.1 \pm 8.0$ & $11 / 32$ & $\begin{array}{l}\text { To investigate the cause of } \\
\text { the increase in the orientation } \\
\text { and variability of SVV among } \\
\text { USN patients }\end{array}$ & SVV \\
\hline $\begin{array}{l}\text { Fukata et al. } \\
(2020)^{29}\end{array}$ & $\begin{array}{l}\text { Stroke with and without } \\
\text { USN and/or Pusher* and } \\
\text { healthy individuals }\end{array}$ & $66.54 \pm 2.3$ & $30 / 28$ & $\begin{array}{l}\text { To compare direction and } \\
\text { variability in SPV and SVV } \\
\text { among patients with PB with } \\
\text { and without USN. }\end{array}$ & SVV and SPV \\
\hline $\begin{array}{l}\text { Fukata et al. } \\
(2020)^{31}\end{array}$ & $\begin{array}{c}\text { Stroke with and without } \\
\text { Pusher* }\end{array}$ & $66.5 \pm 11.0$ & $30 / 23$ & $\begin{array}{l}\text { To clarify the differences } \\
\text { in SPV with regard to the } \\
\text { measurement starting } \\
\text { position between patients } \\
\text { with and without PB. }\end{array}$ & SPV \\
\hline
\end{tabular}

SD: standard deviation; M: male; F: female; RS: right stroke; LS: left stroke; SVV: subjective visual vertical; SHV: subjective haptic vertical; SPV: subjective postural vertical; *USN: direction, response, or orientation limitations on the opposite side of the brain injury after stroke; ** (PB) Pusher behavior: alteration of postural control and postural inclination on the opposite side of the brain lesion after stroke.

Table 2. Evaluation of the methodological quality of the studies, adapted from the QUADAS tool.

\begin{tabular}{|c|c|c|c|c|c|c|c|}
\hline Author/Year/Reference & 1 & 2 & 5 & 9 & 12 & 13 & Score \\
\hline Kerkhoff $(1999)^{20}$ & N & NC & $P$ & NC & NC & N & $1 / 6$ \\
\hline Karnath, Ferber \& Dichgans, $(2000)^{19}$ & N & NC & P & $P$ & NC & N & $2 / 6$ \\
\hline Saj, Honoré, Coello \& Rousseaux (2005) ${ }^{24}$ & N & N & N & $P$ & NC & N & $1 / 6$ \\
\hline Bonan, Guettard, Leman, Colle \& Yelnik (2006) ${ }^{1}$ & N & $P$ & P & P & NC & $P$ & $4 / 6$ \\
\hline $\begin{array}{l}\text { Bonan, Leman, Legargasson, Guichard } \\
\text { \& Yelnik (2006) })^{16}\end{array}$ & N & $P$ & $P$ & $\mathrm{P}$ & $P$ & $P$ & $5 / 6$ \\
\hline Johannsen, Fruhmann Berger \& Karnath (2006) ${ }^{18}$ & N & $\mathrm{N}$ & $P$ & NC & NC & N & $1 / 6$ \\
\hline Bonan et al. $(2007)^{15}$ & $\mathrm{~N}$ & $P$ & $P$ & $P$ & $P$ & $P$ & $5 / 6$ \\
\hline Barra et al. $(2008)^{14}$ & $\mathrm{~N}$ & NC & P & $P$ & $P$ & N & $3 / 6$ \\
\hline Perennou et al. $(2008)^{2}$ & N & P & NC & $P$ & P & $P$ & $4 / 6$ \\
\hline Paci et al. $(2011)^{21}$ & N & $P$ & $P$ & P & $P$ & $P$ & $5 / 6$ \\
\hline Utz et al. $(2011)^{25}$ & $\mathrm{~N}$ & NC & $P$ & NC & NC & N & $1 / 6$ \\
\hline Funk et al. (2011) ${ }^{17}$ & $\mathrm{~N}$ & NC & $P$ & $P$ & $P$ & N & $3 / 6$ \\
\hline Saeys et al. $(2012)^{10}$ & $N$ & NC & P & $\mathrm{P}$ & P & N & $3 / 6$ \\
\hline Bergmann et al. $(2016)^{30}$ & $\mathrm{~N}$ & NC & $P$ & $P$ & $P$ & $\mathrm{~N}$ & $3 / 6$ \\
\hline Baggio et al. (2016) & N & NC & $P$ & $P$ & P & $P$ & $4 / 6$ \\
\hline Reinhart et al. (2016) ${ }^{23}$ & $\mathrm{~N}$ & NC & $P$ & $P$ & $P$ & N & $3 / 6$ \\
\hline Jamal et al. $(2018)^{26}$ & NC & P & $P$ & $P$ & NC & N & $3 / 6$ \\
\hline Saeys et al. $(2018)^{27}$ & NC & $P$ & $P$ & $P$ & NC & N & $3 / 6$ \\
\hline Mori et al. $(2020)^{28}$ & NC & $P$ & $P$ & $P$ & NC & N & $3 / 6$ \\
\hline Fukata et al. $(2020)^{29}$ & $\mathrm{~N}$ & P & $P$ & $P$ & NC & N & $3 / 6$ \\
\hline Fukata et al. (2020) ${ }^{31}$ & $N$ & $P$ & $P$ & $P$ & NC & N & $3 / 6$ \\
\hline Score & $0 / 21$ & $10 / 21$ & $19 / 21$ & $18 / 21$ & $10 / 21$ & $6 / 21$ & \\
\hline
\end{tabular}

N/O: study did not present this item; P/1: the study presents this item; NC/0: the item is not clear in the study; QUADAS questions: (1) Was the spectrum of participants representative of the participants who will receive the test in practice? (2) Were selection criteria clearly described? (5) Did the whole sample or a random selection of the sample receive verification using a reference standard for diagnosis or, at least, was it confirmed verbally that the sample did not have any disease? (9) Was the execution of the reference standard described in sufficient detail to permit its replication? (12) Were the same clinical data available when test results were interpreted as would be available when the test is used in practice? (13) Were uninterpretable/intermediate test results reported? 
were not placed on the ground ${ }^{19}$. Barra $(2008)^{14}$ and Perennou $(2008)^{22}$ kept their subjects' lower limbs in a fixed position. The other studies did not report the position of the lower limbs. Regarding the devices used for performing the tests, many studies used specific software with a light line in a dark setting or with background changes ${ }^{17,23}$.

In performing the test, Kerkhoff(1999) did not describe the initial angulation ${ }^{20}$. Karnath et al. (2000) ${ }^{19}$ and Johannsen et al. $(2006)^{18}$ used $35^{\circ}$; Saj (2005) ${ }^{24} 45^{\circ}$; Bonan (2007) $)^{15}$ and Bonan $(2006)^{16} 40^{\circ}$; Bonan $(2006)^{17} 60^{\circ}$; and Barra (2008) $)^{14}$, Jamal et al. $(2018)^{26}$ and Mori et al. $(2020)^{28} 30^{\circ}$. Perennou $(2008)^{22}$ varied the starting point from 15 to $45^{\circ}$, Paci $(2011)^{21}$ from 28 to $88^{\circ}$ and Saeys $(2012)^{10}$ from 0 to $20^{\circ}$. Utz $(2011)^{25}$, Funk $(2011)^{17}$ and Reinhart $(2016)^{23}$ used $20^{\circ}$ as the starting angulation. Sayes et al. (2018) ${ }^{27}$ used a range of $20^{\circ}$. Therefore, the angulation ranged from 0 to $88^{\circ}$.

The number of repetitions in these assessments ranged from 6-10 times, and the authors explained that half of the repetitions were in the counterclockwise direction and the other half in the clockwise direction ${ }^{1,15,16,18-20,23,26,28}$. We can also highlight that the movement speed of the light in the SVV test ranged from 1 to $5^{\circ} / \mathrm{s}^{28,31}$.

\section{Subjective haptic vertical}

Four studies evaluated the SHV in this review ${ }^{9,20,22,25}$. Of these, two studies, Kerkhoff (1999) ${ }^{20}$ and Utz (2011) ${ }^{25}$, compared individuals with and without unilateral spatial neglect (USN) with a healthy group. Perennou (2008) ${ }^{22}$ evaluated individuals who had suffered a stroke in both hemispheres with a healthy group, and Baggio (2016) ${ }^{9}$ also analyzed individuals who had suffered a stroke in both hemispheres. Kerkhoff $(1999)^{20}$ evaluated the SHV with different levels of head tilt, and Utz (2011) evaluated the SHV in two planes, frontal and sagittal.

In all of these studies, during the evaluations, the individuals were blindfolded in a seated position. In three studies ${ }^{9,22,25}$, the authors performed stabilization of the head, trunk and lower limbs; and in one, they stabilized the chin and head ${ }^{20}$. The length of the bar ranged from 15 to $40 \mathrm{~cm}$, and the distance from the individual to the device ranged from 0.4 to $0.5 \mathrm{~m}$.

The initial angle for performing the SHV test ranged from $15-45^{\circ 22}$ or was $20^{\circ 25}$ or $15^{\circ 9}$. Therefore, overall, the angulation ranged from 15 to $45^{\circ}$. In most of the studies, ten repetitions were performed: half of them clockwise and the other half counterclockwise.

\section{Subjective postural vertical}

Eight studies evaluated the SPV in this review ${ }^{9,10,19,22,27,29,30,31}$. Four studies evaluated patients with Pusher syndrome ${ }^{19,29,30,31}$. In the evaluations, individuals were positioned seated on a tilting chair with head, trunk and lower limbs stabilized; and were blindfolded. The exception to this was Bergmann et al. (2016), who determined the SPV while their subjects were standing ${ }^{30}$. Other authors described positions of the lower limbs in which they were not placed on the ground ${ }^{9,10,27,29,31}$, while Perennou $(2008)^{22}$ described lower limbs supported on the ground.

The chairs were rotated passively to the point of a given angulation. Karnath et al. (2000) ${ }^{19}$ started the test at $35^{\circ}$, and Baggio $(2016)^{9}$ at $15^{\circ}$. Perennou $(2008)^{22}$ varied the initial angle from 15 to $45^{\circ}$, Saeys $(2012)^{10}$ from 0 to $20^{\circ}$, Bergmann $(2016)^{30}$ from 12 to $18^{\circ}$ and Fukata et al. (2020) ${ }^{29}$ and Fukata et al. (2020) $)^{31}$ over a range from 15 to $20^{\circ}$. Therefore, overall, the angulation ranged from 0 to $45^{\circ}$. The individual was instructed to adjust the chair to the vertical position through a verbal command, except in Saeys (2012) ${ }^{10}$ and Saeys $(2018)^{27}$, in which the adjustments were made by remote control. Perennou (2008) ${ }^{22}$, Baggio $(2016)^{9}$, Fukata et al. $(2020)^{29}$ and Fukata et al. $(2020)^{31}$ described the rotation speed of the chair, and this was less than or equal to $1.5^{\circ} / \mathrm{s}$. The number of repetitions in the test ranged from 6 to 10 times.

\section{DISCUSSION}

This systematic review was one of the first to discuss and explore the methods of assessing verticality perceptions among post-stroke individuals, and it provides crucial information on how to perform the tests in upcoming studies, in order to standardize the evaluation.

\section{Subjective visual vertical}

In all studies, the evaluation of SVV perceptions took place in a dark room with blindfolded individuals positioned on a chair. In most of these studies, the head, chin and trunk were stabilized in the vertical position. Recently, Molina et al. (2019) showed that the type of protocol used for determining the SVV did not have any effect ${ }^{32}$. This suggests that there is no difference in estimating the SVV between use of an upright standing position and use of a sitting position.

The methodological differences between the studies were mainly related to the length of the luminous stimulus, the distance between it and the individual evaluated, and the initial angulation. The number of repetitions ranged from 6-10 times, and the individuals indicated the vertical position through verbal command in the majority of the studies. Utz $(2011)^{10}$ and Saj (2005) $)^{24}$ used visual and proprioceptive information. Most studies evaluated SVV among individuals with USN after stroke $e^{20,24,17,28,29}$, with balance impairment ${ }^{1,15}$ and with balance recovery ${ }^{16}$, and individuals with Pusher syndrome ${ }^{18,19,21,22,29}$.

\section{Subjective haptic vertical}

To evaluate the SHV, a bar was used in some studies, and the individuals were seated on a chair and blindfolded. There were methodological differences among the studies, such as the length of the bar, the distance from the individual to the device and the initial angulation of the test. These studies indicated that assessment of SHV perceptions should be done among individuals with $\mathrm{USN}^{9,20,22}$. 


\section{Subjective postural vertical}

Certain factors may interfere with evaluation of SPV perceptions, such as the possibility of head and trunk movements and the somatosensory input. There were methodological differences among the SPV tests used, such as the subjects' positioning, whether their lower limbs were on the ground and the chair speed ${ }^{9,20,22}$. SPV tests were also used among individuals with Pusher syndrome after stroke ${ }^{9,20,22,31}$, and with USN after stroke ${ }^{29}$.

\section{Limitations and clinical applications}

Although all of these studies evaluated individuals poststroke condition, the samples were very heterogeneous regarding the number of participants and their ages, brain lesions and length of time since the stroke. However, after analysis of all the studies included, we were able to discern some consistent tendencies regarding the methodology for carrying out these evaluations, including, for example, placing the examinee in a sitting position. The evaluations on SVV perceptions took place with a light stimulus in a dark room, and individuals indicated the vertical position through a verbal response. In evaluations on SHV, blindfolded individuals had to adjust a bar to an upright position, and in evaluations on SPV, blindfolded individuals adjusted themselves to the vertical position in a chair that had previously been rotated passively. Most studies conducted evaluations on verticality perceptions among patients with USN, Pusher syndrome and balance recovery after stroke.

In this review, we highlighted that most of the studies had a negative aspect in questions 1 and 13 of the QUADAS tool. The sample was not always representative, and uninterpretable/ intermediate test results were not well reported. According to the adapted QUADAS protocol from Conceição et al. (2018) ${ }^{13}$, considering these six questions, the studies with better methodological quality were the following: Bonan et al. $(2006)^{16}$; Bonan et al. (2006)'; Bonan et al. (2007) ${ }^{15}$; Perennou et al. $(2008)^{22}$; Paci et al. $(2011)^{21}$; and Baggio et al. (2016) .

It was clear that there was high variability in the methodological aspects of evaluations on SVV, SHV and SPV. The initial angulation of the test, the device used and the patient position require standardization. We found three systematic reviews on the methodological approaches used in verticality tests after stroke ${ }^{13,32,33}$. However, only our review has investigated the use of all approaches to verticality perceptions after stroke. Therefore, we have put forward an evaluation protocol for SVV, SHV and SPV to help future researchers/clinicians, which is presented in Table 3. Nonetheless, in the light of the complex development of new strategies for motor control among acute and chronic stroke patients, evaluations on verticality perceptions should be adapted according to the stroke phase. We acknowledge that there are different limitations to evaluations on verticality perceptions in the acute phase of stroke. First of all, patients in the acute phase may be clinically unstable, may have poor trunk control and may have difficulty in understanding the test. Because of this clinical situation, the patient position needs to be adapted ( for example, through use of a semi-recumbent position). In addition, it may be necessary to test patients in bed. Furthermore, verticality devices need to be easy to handle and portable.

In conclusion, we conclude that there is high variability in assessments on verticality perceptions, due to patient positions, devices used, numbers of repetitions and initial angles for starting the tests. Therefore, we have proposed a protocol for assessing each type of verticality, based on the similarities found between the studies included in this review. Furthermore, assessment of verticality perceptions is a valuable tool for cases of USN, Pusher syndrome and balance disorders after stroke.

Table 3. Instructions for assessment of verticality perceptions.

\begin{tabular}{|c|c|c|c|}
\hline & SVV & SHV & SPV \\
\hline Device & $\begin{array}{l}\text { Computerized, vertical } \\
\text { luminous stimulus and virtual } \\
\text { reality helmet }\end{array}$ & Manually rotated bar & $\begin{array}{c}\text { Manual, hydraulic or motorized } \\
\text { chair }\end{array}$ \\
\hline Patient's position & $\begin{array}{c}\text { Seated or upright standing } \\
\text { position }\end{array}$ & Seated & Seated \\
\hline Distance (patient to device) & 0.5 to $2.5 \mathrm{~m}$ & 0.4 to $0.5 \mathrm{~m}$ & - \\
\hline Device measurement & 7.5 to $30 \mathrm{~cm}$ (rod) & 15 to $40 \mathrm{~cm}$ (rod) & - \\
\hline Velocity (\%/s) & - & - & 1.5 \\
\hline Lighting & Dark room & Blindfolded & Blindfolded \\
\hline Overall support & Head, chin and trunk fixed* & Head, trunk and limbs fixed* & Head, trunk and limbs fixed* \\
\hline Number of repetitions (range) & $10(6-10)$ & $10(6-10)$ & $10(6-10)$ \\
\hline Directions & $\begin{array}{l}\text { Clockwise and } \\
\text { counterclockwise }\end{array}$ & Vertical, horizontal and oblique & Sagittal and frontal planes \\
\hline Initial degree (range) & $35(15-88)$ & $17.5(15-45)$ & $20(15-45)$ \\
\hline Data analysis & Average and median & Average & Average \\
\hline
\end{tabular}

SVV: subjective visual vertical; SHV: subjective haptic vertical; SPV: subjective postural vertical; * suggested only for patients with no trunk control. 
1. Bonan IV, Guettard E, Leman MC, Colle FM, Yelnik AP. Subjective visual vertical perception relates to balance in acute stroke. Arch Phys Med Rehabil. 2006 May 1;87(5):P642-6. https://doi. org/10.1016/j.apmr.2006.01.019

2. Pérennou D, Piscicelli C, Barbieri G, Jaeger M, Marquer A, Barra J. Measuring verticality perception after stroke: why and how? Neurophysiol Clin. 2014 Jan;44(1):25-32. https://doi.org/10.1016/j. neucli.2013.10.131

3. Bronstein AM. The interaction of otolith and proprioceptive information in the perception of verticality: the effects of labyrinthine and CNS disease. Ann NY Acad Sci. 1999 May 28;871:324-33. https:// doi.org/10.1111/j.1749-6632.1999.tb09195.x

4. Pereira CB, Kanashiro AK, Maia FM, Barbosa ER. Correlation of impaired subjective visual vertical and postural instability in Parkinson's disease. J Neurol Sci. 2014 Nov 15;346(1-2):P60-5. https://doi.org/10.1016/j.jns.2014.07.057

5. Tribukait A, Bergenius J, Brantberg K. The subjective visual horizontal for different body tilts in the roll plane: characterization of normal subjects. Brain Res Bull. 1996;40(5-6):375-81. https://doi. org/10.1016/0361-9230(96)00130-XGet

6. Bisdorff AR, Wolsley CJ, Anastasopoulos D, Bronstein AM, Gresty MA. The perception of body verticality (subjective postural vertical) in peripheral and central vestibular disorders. Brain. 1996 Oct 1;119(5):1523-34. https://doi.org/10.1093/brain/119.5.1523

7. Santos TEG, Favoretto DB, Toostani IG, Nascimento DC, Rimoli BP, Bergonzoni E, et al. Manipulation of human verticality using highdefinition transcranial direct current stimulation. Front Neurol. 2018 Oct 22;9:825. https://doi.org/10.3389/fneur.2018.00825

8. Cuturi LF, Gori M. Biases in the visual and haptic subjective vertical reveal the role of proprioceptive/vestibular priors in child development. Front Neurol. 2019 Jan 7;9:1151. https://doi. org/10.3389/fneur.2018.01151

9. Baggio JAO, Mazin SSC, Alessio-Alves FF, Barros CGC, Carneiro AAO, Leite JP, et al. Verticality perceptions associate with postural control and functionality in stroke patients. PLoS One. $2016 \mathrm{Mar}$ 8;11(3):e0150754. https://doi.org/10.1371/journal.pone.0150754

10. Saeys W, Vereeck L, Truijen S, Lafosse C, Wuyts FP, Van de Heyning P. Influence of sensory loss on the perception of verticality in stroke patients. Disabil Rehabil. 2012 Apr 16;34(23):1965-70. https://doi.org /10.3109/09638288.2012.671883

11. Liberati A, Altman DG, TetzlaffJ, Mulrow C, Gøtzsche PC, loannidis JPA, et al. The PRISMA statement for reporting systematic reviews and meta-analyses of studies that evaluate healthcare interventions: explanation and elaboration. BMJ. 2009 Jul 21;339:b2700. https:// doi.org/10.1136/bmj.b2700

12. Whiting P, Rutjes AWS, Reitsma JB, Bossuyt PMM, Kleijnen J. The development of QUADAS: a tool for the quality assessment of studies of diagnostic accuracy included in systematic reviews. BMC Med Res Methodol. 2003 Nov 10;3:25. https://doi.org/10.1186/1471-2288-3-25

13. Conceição LB, Baggio JAO, Mazin SC, Edwards DJ, Santos TEG. Normative data for human postural vertical: a systematic review and meta-analysis. PLoS One. 2018 Sep 28;13(9):e0204122. https://doi. org/10.1371/journal.pone.0204122

14. Barra J, Benaim C, Chauvineau V, Ohlmann T, Gresty M, Pérennou D. Are rotations in perceived visual vertical and body axis after stroke caused by the same mechanism? Stroke. 2008 Nov;39(11):3099-101. https://doi.org/10.1161/STROKEAHA.108.515247

15. Bonan IV, Hubeaux K, Gellez-Leman MC, Guichard JP, Vicaut E, Yelnik AP. Influence of subjective visual vertical misperception on balance recovery after stroke.J Neurol Neurosurg Psychiatry. 2007 Jan;78(1):49-55. https://doi.org/10.1136/jnnp.2006.087791

16. Bonan IV, Leman MC, Legargasson JF, Guichard JP, Yelnik AP.
Evolution of subjective visual vertical perturbation after stroke. Neurorehabil Neural Repair. 2006 Dec 1;20(4):484-91. https://doi. org/10.1177/1545968306289295

17. Funk J, Finke K, Müller HJ, Utz KS, Kerkhoff G. Visual context modulates the subjective vertical in neglect: evidence for an increased rod-and-frame-effect. Neuroscience. 2011 Jan 26;173:124-34. https://doi.org/10.1016/j.neuroscience.2010.10.067

18. Johannsen L, Berger MF, Karnath $\mathrm{H}-\mathrm{O}$. Subjective visual vertical (SVV) determined in a representative sample of 15 patients with pusher syndrome.J Neurol. 2006 Oct;253(10):1367-9. https://doi. org/10.1007/s00415-006-0216-x

19. Karnath HO, Ferber S, Dichgans J. The origin of contraversive pushing: evidence for a second graviceptive system in humans. Neurology. 2000 Nov 14;55(9):1 298-304. https://doi.org/10.1212/WNL.55.9.1298

20. Kerkhoff G. Multimodal spatial orientation deficits in left-sided visual neglect. Neuropsychologia. 1999 Nov;37(12):1387-405. https:// doi.org/10.1016/S0028-3932(99)00031-7

21. Paci M, Matulli G, Megna N, Baccini M, Baldassi S. The subjective visual vertical in patients with pusher behaviour: a pilot study with a psychophysical approach. Neuropsychol Rehabil. 2011 Aug 8;21(4):539-51. https://doi.org/10.1080/09602011.2011.583777

22. Pérennou DA, Mazibrada G, Chauvineau V, Greenwood R, Rothwell J, Gresty MA, et al. Lateropulsion, pushing and verticality perception in hemisphere stroke: a causal relationship? Brain. 2008 Sep;131(9):2401-13. https://doi.org/10.1093/brain/awn170

23. Reinhart S, Schaadt AK, Keller I, Hildebrandt H, Kerkhoff G, Utz K. Rotational coherent dot movement normalizes spatial disorientation of the subjective visual vertical in patients with rightsided stroke. Neuropsychologia. 2016 Nov;92:174-80. https://doi.org/10.1016/j. neuropsychologia.2016.04.027

24. Saj A, Honoré J, Coello Y, Rousseaux M. The visual vertical in the pusher syndrome: influence of hemispace and body position. J Neurol. 2005 Aug;252(8):885-91. https://doi.org/10.1007/s00415005-0716-0

25. Utz KS, Keller I, Artinger F, Stumpf O, Funk J, Kerkhoff G. Multimodal and multispatial deficits of verticality perception in hemispatial neglect. Neuroscience. 2011 Aug 11;188:68-79. https://doi. org/10.1016/j.neuroscience.2011.04.068

26. Jamal K, Leplaideur S, Rousseau C, Chochina L, MoulinetRaillon A, Bonan I. Disturbances of spatial reference frame and postural asymmetry after a chronic stroke. Exp Brain Res. 2018 Aug;236(8):2377-85. https://doi.org/10.1007/s00221-018-5308-1

27. Saeys W, Herssens N, Verwulgen S, Truijen S. Sensory information and the perception of verticality in post-stroke patients. Another point of view in sensory reweighting strategies. PLoS One. 2018 Jun 29;13(6):e0199098. https://doi.org/10.1371/journal.pone.0199098

28. Mori K, Nakamura K, Hashimoto S, Wakida M, Hase K. Novel characterization of subjective visual vertical in patients with unilateral spatial neglect. Neurosci Res. 2021 Feb;163:18-25. https:// doi.org/10.1016/j.neures.2020.02.005

29. Fukata K, Amimoto K, Fujino Y, Inoue M, Inoue M, Takahashi Y, et al. Influence of unilateral spatial neglect on vertical perception in post-stroke pusher behavior. Neurosci Lett. 2020 Jan 10;715:134667. https://doi.org/10.1016/j.neulet.2019.134667

30. Bergmann J, Krewer C, Selge C, Müller F, Jahn K. The subjective postural vertical determined in patients with pusher behavior during standing. Top Stroke Rehabil. 2016 Jun;23(3):184-90. https://doi.org/ 10.1080/10749357.2015.1135591

31. Fukata K, Amimoto K, Fujino Y, Inoue M, Inoue M, Takahashi Y, et al. Starting position effects in the measurement of the postural vertical for pusher behavior. Exp Brain Res. 2020 Oct;238(10):2199-2206. https://doi.org/10.1007/s00221-020-05882-z 
32. Molina F, Lomas-Vega R, Obrero-Gaitán E, Rus A, Almagro DR,

Del-Pino-Casado R. Misperception of the subjective visual vertical in neurological patients with or without stroke: a meta-analysis. NeuroRehabilitation. 2019;44(3):379-88. https://doi.org/10.3233/ NRE-182642
33. Piscicelli C, Pérennou D. Visual verticality perception after stroke: a systematic review of methodological approaches and suggestions for standardization. Ann Phys Rehabil Med. 2017 Jun;60(3):208-16. https://doi.org/10.1016/j.rehab.2016.02.004 